\title{
La lucha de las sufragistas ${ }^{1}$
}

\section{The Scramble of the Suffragette Movement}

\author{
Mauricio Tayupanta
}

Recepción: 28 de Agosto de 2015

Aceptación: 4 de septiembre de 2015

\section{Resumen}

A finales del siglo XIX Emma Goldman, Emily Davson, Carmen Karry crearon el movimiento sufragista inglés, considerando que Holanda y Gran Bretańa eran gobernados por mujeres: la Reina Guillermina, y la Reina Victoria. En la misma época, Paraguay tenía como protagonista a la mujer, pero no tenía derechos políticos.

En 1907 el Gran Ducado de Finlandia concedió a la mujer el voto universal, secreto y directo sin tomar en cuenta su raza, condición social o estrato económico. Matilde Hidalgo en Ecuador, fue la primera mujer ecuatoriana en exigir y lograr un bachillerato completo. También fue la primera mujer en votar. Ahora la mujer vive su derecho a elegir y ser elegida. Muchas mujeres han ocupado el sillón presidencial en Sudamérica: Lidia Gueiler Tejada en Bolivia, María Estela Martínez en Argentina, Violeta Chamorro en Nicaragua, Laura Chinchilla en Costa Rica, Michelle Bachelet en Chile, Cristina Fernández en Argentina y Dilma Rousseff en Brasil.

Palabras clave: sufragistas, voto, femenino, mujeres, democracia.

\section{Abstract}

BBy the end of nineteen-century, Emma Goldman, Emily Davson and Carmen Karry created the Suffragette movement, considering that the Netherlands and Great Britain were ruled by women: Queen Guillemin and Queen Victoria. At the same time, Paraguay saw women taking leading roles, but without political rights.

On 1907, the Grand Duchy of Finland, granted women the universal right to vote in secrecy, regardless of their race, social or economic status. In Ecuador, Matilde Hidalgo was the first woman claiming her right to study and finally achieving her degree. She also became the first woman to vote. Now women know their right to choose and to be chosen. Many women have come to occupy the presidential seat in South America: Lidia Gueiler Tejada in Bolivia, María Estela Martínez in Argentina, Violeta Chamorro in Nicaragua, Laura Chinchilla in Costa Rica, Michel Bachelet in Chile, Cristina Fernández in Argentina and Dilma Rousseff in Brasil.

Keywords: suffragette, vote, female, woman, democracy

1 El artículo carece de bibliografía dado que refleja la recopilación de la memoria histórica del Dr. Ricardo Ordóńez. 


\section{Introducción}

T as sufragistas fue un movimiento femenino nacido al amparo de la sociedad inglesa de la época victoriana y la norteamericana posterior a la Guerra de Secesión del siglo XIX. Su anhelo y finalidad era el dar a la mujer la condición plena de ciudadana de un país, capaz de elegir y ser elegidas en puestos de designación popular, como lo eran en ese entonces los varones, exclusivamente. En un principio el movimiento sufragista fue repudiado por la sociedad y en muchos casos criticado, curiosamente, por las propias mujeres conservadoras, moralistas y envueltas en una trastocada religiosidad protestante, o la atrasada y casi inquisitorial moral católica de la época, las cuales consideraban a la política como una actividad puramente masculina. A las mujeres que pretendían el sufragio como un derecho connatural a su condición de seres humanos, se las tildó de todo epíteto: desde locas, histéricas o bárbaras, hasta herejes o destructoras de la sociedad y de la moral pública. Por esa razón, cuando las Sufragistas eran frecuente y ferozmente reprimidas por la policía a ojos vista de todo el mundo, tanto varones como anti sufragistas y ministros del culto aplaudían tan represor comportamiento.

Como ciertos grupos de mujeres se oponían al voto femenino, era de esperarse que los grupos organizados de varones, como lo eran los sindicatos, gremios laborales y partidos políticos -en los cuales se prohibía la participación de las damas- se opusieran también a este movimiento. Pero la mujer trabajaba, era obrera fabril, trabajaba el campo, era artesana, amén de madre, esposa, maestra y comerciante. Pagaba impuestos y a la par y en buena parte de Europa y América Latina, había comenzado a educarse y alfabetizarse. Con el conocimiento logró abrir sus ojos y se supo un ser humano actuante frente a la sociedad tenedora de derechos y no solo cumplidora de deberes.

Por ello, mujeres brillantes como Emma Goldman, Emily Davson, Carmen Karry y otras visionarias llevaron avante el movimiento sufragista inglés, elevando como bandera el hecho de que a la época, 
dos de los países más ricos de Europa y dueños de sendos y extensos imperios coloniales como lo eran Holanda y la Gran Bretaña, eran gobernados por mujeres: la Reina Guillermina, y la Reina Victoria.

En el Paraguay de la posguerra de la Triple Alianza, la mujer -que era el núcleo mayor de la población en una escala de 10 mujeres por cada hombre- lo hacía todo, desde labrar el campo hasta vender en los mercados de Asunción pero no tenía derechos políticos.

Con toda esta enseńanza entre las manos y el convencimiento de que la mujer tenía derechos tanto como deberes, constituyeron en Berlín, en 1904, la asociación internacional de mujeres Sufragistas con delegaciones de toda Europa, Estados Unidos y de algunas naciones de la América. En dicho congreso se tomaron muy en cuenta los tímidos avances norteamericanos en donde los estados de Nueva Jersey y Wyoming -donde se concedió el voto a la mujer pero solo para aquella de raza blanca- la mujer indígena o afro descendiente quedó al margen de este derecho, comportamiento muy norteamericano de principios del siglo XX.

Sin embargo fue en 1907, en el entonces Gran Ducado de Finlandia que era parte del Imperio Zarista ruso, que se concedió a la mujer el voto Universal secreto y directo sin tomar en cuenta su raza, condición social o estrato económico.

Al finalizar la Primera Guerra Mundial y desmoronarse por entero el mundo decimonónico y sus parámetros de conducta y valoración de todo lo hasta entonces tenido como valedero -sobre todo después de que durante la guerra las mujeres desempeñaron un papel determinante como mano de obra fabril, en los correos, telégrafos, trabajando el campo- quedó bien claro el potencial femenino en todos los órdenes y, al enfrentar los turbulentos ańos 20, en toda Europa comenzó a cambiar su legislación. Desaparecieron los imperios Ruso, Alemán, Otomano y Austrohúngaro y de sus ruinas aparecieron varios estados nacionales de corte republicano, cuyas constituciones eran de corte liberal. Las nacientes repúblicas concedieron a la mujer los mismos derechos políticos que a los hombres y así se destacaron damas como Rosa Luxemburgo, 
Kruwskya Ullanova y Carmen Campoamor que cambiaron para siempre la faz de la política y la izquierda europea.

A partir de los años $30 \mathrm{y}$ con el advenimiento de los partidos y movimientos fascistas, todos los logros sociales, políticos y laborales, se fueron al traste. Este problema se lo sintió sobre todo en la España de Franco, la Italia de Musolini, y en la Alemania de Hitler donde el status quo de la mujer retrocedió significativamente. Al finalizar la contienda, la Organización de las Naciones Unidas determinó los derechos políticos de la mujer como los mismos del hombre, sin distingo de raza, lengua o religión.

Donde ha ido evidentemente más despacio el avance de los derechos políticos del mal llamado "sexo débil", ha sido en las naciones africanas y del cercano Oriente de cultura musulmana radical, donde la mujer como tal, está sujeta a la manda del padre, primero, o del esposo después y a falta de estos, del hermano mayor o del hijo primogénito. En los estados sujetos a las leyes Coránicas, la mujer soltera, casada o viuda carece de derechos personales y aún peor es la situación de la mujer divorciada.

El camino de las Sufragistas en la América Latina, no fue nada fácil. Verbigracia la usanza moralista religiosa heredada de la época colonial española y de los gobiernos conservadores decimonónicos que rigieron los destinos del continente a raíz de la independencia, por ello aquí en estas tierras hispano-luso-americanas se veía con muy malos ojos por parte de la sociedad, patriarcal y machista que la mujer se eduque y mucho más que vote, elija, evidentemente jamás ser elegida. Para los hispanoamericanos de entonces las manifestaciones de las sufragistas europeas y norteamericanas eran "pataleos de gringas locas, sin marido que las discipline".

Pero muy aparte de estos pareceres machistas y trasnochados toda la América Latina se asombró ante la valentía y decisión de la mujer paraguaya la cual a puro esfuerzo de sus manos iba levantando un país arrasado por la Guerra de la Triple Alianza donde se calcula murieron más de 1200000 personas y sobrevivieron al genocidio 2200000 
personas; apenas veinte mil eran varones, ya sean estos nińos menores de diez años, inválidos de guerra o sobrevivientes de la guerra, el resto eran mujeres que trabajaron de todo y en todo oficio, desde el trabajo del campo hasta labores fabriles, de "burreritas" vendedoras de mercado así como las durísimas labores en el puerto de Asunción de Paraguay. Pero estas paraguayas de hierro, que además de todo ello parían un hijo cada año para repoblar y levantar el destrozado país, solo tenían deberes, deberes y más deberes.

¿Pero derechos? Esa palabra no existía en el diccionario de la mujer paraguaya. Esa experiencia sumada a la participación de la Soldadera Mexicana o el de las tropeńas que iban junto a las montoneras alfaristas en Ecuador, nos revela a una mujer ajena a la educación o a la vida urbana y a su reciente y escaza alfabetización. Pero al igual que varias heroínas de la independencia, sabían disparar, repartir el rancho, acaudillar, dirigir las tropas, enfrentar, vencer al enemigo y así cooperar con la revolución que fuere. Esto deja claro que el papel puramente maternal y doméstico de la mujer es una ficción y que ella es dueña de capacidades, de derechos y de deberes que cumplir frente a la sociedad.

La experiencia ecuatoriana es muy interesante. Ocurrió que en la ciudad de Loja, nace dońa Matilde Hidalgo Navarro de Procel (1889-1974), quien se convertiría en la primera mujer ecuatoriana en requerir, exigir y lograr la realización de un bachillerato completo, situación reservada a los varones. Consiguió dicho logro a pesar de la repulsa social que se cernió sobre ella desde todos los ámbitos: sociales, familiares y hasta religiosos. Caso importante el del cura de su parroquia -San Sebastián- que la obligaba a escuchar la santa misa desde escalinatas exteriores de la iglesia.

Ella, impertérrita y siempre apoyada por la figura de su madre, la costurera doña Carmen Navarro Castillo, estudió con ahínco y consiguió graduarse en la facultad de medicina de Cuenca, a pesar de la cerrada oposición de muchos de sus maestros y compañeros que trataban de excluirla de las aulas. Siendo ella dueña de una profesión y carrera, solicitó en 1924 al presidente de la República, el Dr. José Luis Tamayo, 
que considere su derecho a votar, situación que la consigue luego de una consulta ministerial. Más tarde, luego de un gran esfuerzo político, personal y grupal, las ecuatorianas consiguieron ser reconocidas como personas dueñas de su derecho a votar, elegir y ser elegidas en 1929. Pocos años después Matilde Hidalgo de Procel y dońa Nela Martínez Espinoza fueron las dos primeras mujeres en ocupar un escaño en el Congreso Nacional.

Un caso muy curioso se dio en 1927 en la localidad Uruguaya de Cerro-Chato. Un pintoresco pueblo que se asienta en una antigua posta de la ruta de las diligencias, del correo y de las tropas de ganado; donde se encuentran las fronteras de los departamentos de Treinta y Tres, Florida y Durazno. Como no se determinaba a cuál de los tres departamentos debía pertenecer el pueblo, se consideró oportuno llamar a un Plebiscito, el cual tuvo lugar el 3 de junio de 1927. A este evento fueron convocadas las mujeres, por vez primera en la historia de la América Latina, a expresar su voluntad en las urnas. Si bien es la primera vez que sufragaban las damas en el continente, fue un asunto puramente regional y las uruguayas debieron esperar casi veinte ańos para que se sancionara la ley Nacional del Sufragio femenino.

En 1946, en la república Argentina, la inolvidable "Evita", doña Eva Duarte de Perón, en su papel de presidenta del sector femenino del partido Justicialista Peronista argentino, presentó un proyecto de Ley para el Sufragio Femenino, ley que fue discutida y sancionada por el Congreso de la Nación y aceptado por este. La nueva Ley fue proclamada y registrada en 1946 con alcance nacional. Al siguiente ańo se sancionó una ley similar en el Palacio de Estévez de Montevideo para la República Oriental del Uruguay. A partir de entonces y poco a poco, el siglo XX contempló con beneplácito como las naciones hispanoamericanas fueron sancionando leyes en ese mismo sentido.

Ahora la mujer es dueña de su derecho a elegir, ser elegida y ha ocupado cargos determinantes en la vida política del continente como lo fuera la Dra. Lidia Gueiler Tejada, quien llegó a ocupar la presidencia de Bolivia durante el Interinato 1979-1980 para admiración de todo 
un continente. Antes que ella María Estela Martínez viuda de Perón fue Vicepresidenta y Presidenta de la Argentina y después de ellas toda una pléyade de damas como Doña Violeta Chamorro, en Nicaragua, Laura Chinchilla en Costa Rica, Michelle Bachelet en Chile, Cristina Fernández de Kirchner en Argentina y Dilma Rousseff en Brasil, han constelado el cielo americano con el bien-hacer de las mujeres en la política. 